Document downloaded from:

http://hdl.handle.net/10251/51379

This paper must be cited as:

Vincent Vela, MC.; Cuartas Uribe, BE.; Alvarez Blanco, S.; Lora García, J. (2011). Analysis of fouling resistances under dynamic membrane filtration. Chemical Engineering and Processing: Process Intensification. 50:404-408. doi:10.1016/j.cep.2011.02.010.

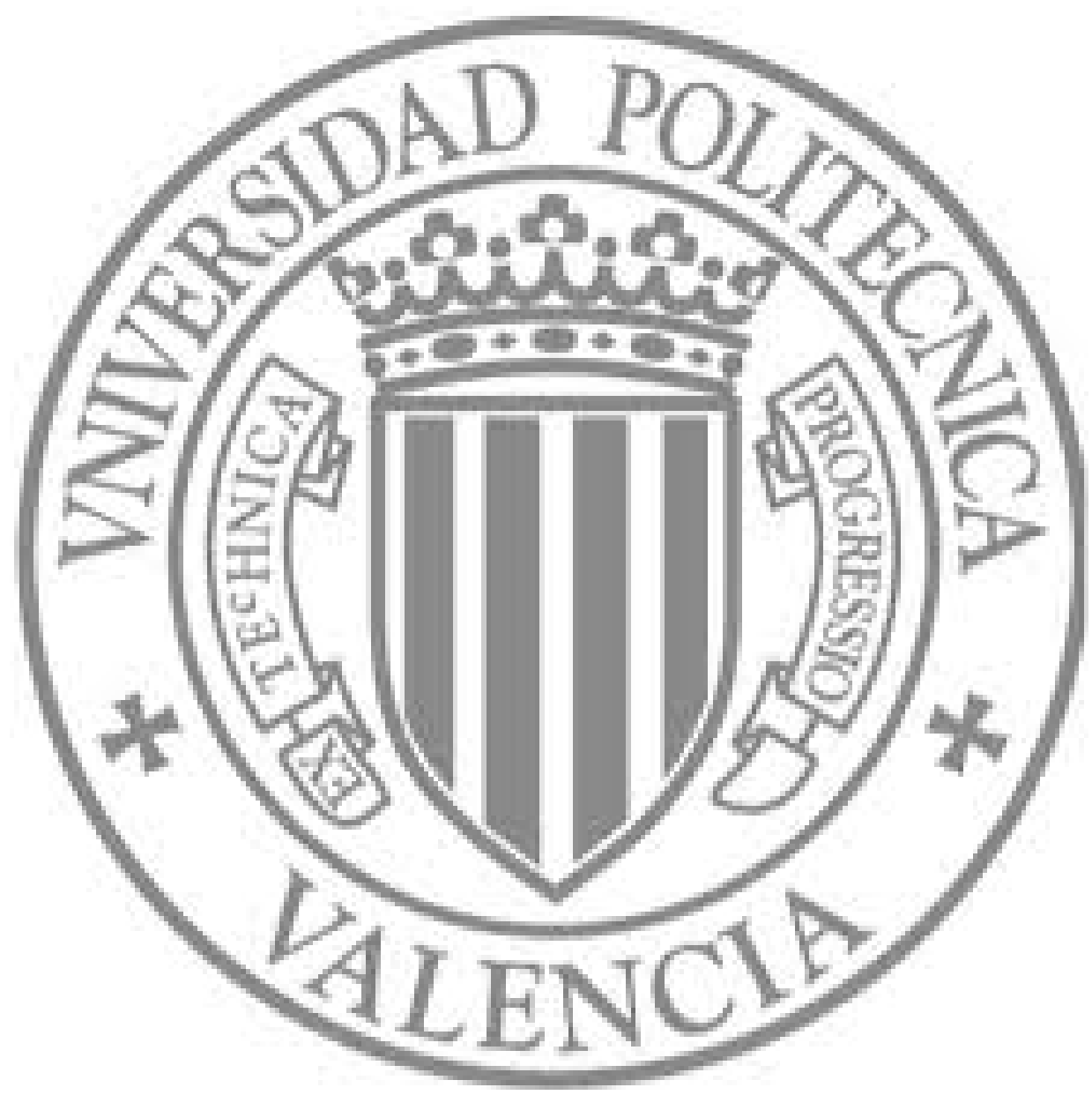

The final publication is available at

http://dx.doi.org/10.1016/j.cep.2011.02.010

Copyright Elsevier 


\title{
Analysis of fouling resistances under dynamic membrane filtration
}

Cinta Vincent-Vela ${ }^{(1)} *$, Beatriz Cuartas-Uribe ${ }^{(1)}$, Silvia Álvarez-Blanco ${ }^{(1)}$, Jaime LoraGarcía $^{(1)}$, Enrique Bergantiños-Rodríguez ${ }^{(2)}$

${ }^{(1)}$ Department of Chemical and Nuclear Engineering, Polytechnic University of Valencia, C/Camino de Vera s/n 46022 Valencia, Spain. Tel. +34 963877000 Ext. 79387; Fax.+34 963877639; e-mail: mavinve@iqn.upv.es

${ }^{(2)}$ Department of Chemical Engineering, Polytechnical Institute José A. Echeverría, Ave. 114, No. 11901, Havana, Cuba.

*Corresponding author.

\begin{abstract}
The mechanisms of fouling in the ultrafiltration of polyethylene glycol (PEG) are analyzed using the complete blocking and the intermediate blocking Hermia's models adapted to crossflow filtration. ${ }^{1}$ The parameters of these models were theoretically estimated. The predicted results were compared with experimental data. Ultrafiltration experiments were performed with Carbosep M2 monotubular ceramic (Orelis, S.A. (France)). The fouling ultrafiltration experiments were carried out at a constant temperature and feed concentration and different feed flow rates and transmembrane pressures. The precision in the predictions is very high. The results showed that the phenomenon controlling fouling was intermediate blocking for high fouling conditions.
\end{abstract}


Keywords:, Crossflow ultrafiltration, Modelling, Polyethylene glycol, Fouling.

\section{Introduction}

Ultrafiltration uses a finely porous membrane to separate water and microsolutes from macromolecules and colloids. ${ }^{2}$ The first large successful application of ultrafiltration was the recovery of electrocoat paint in automobile plants. Later, a number of significant applications developed in the food industry ${ }^{3}$, first in the production of cheese, then in the production of apple and other juices and, more recently, in the production of beer and wine. Industrial wastewater and process water treatment is a growing application, but high costs limit growth. However, it is used to treat small, concentrated waste streams from particular point sources before they are mixed with the general sewer stream. Ultrafiltration is also used if the value of the components to be separated is sufficient to offset the cost of the process. Examples exist in food processing, in which the ultrafiltered concentrate is used to produce a high-value product, or in the production of ultrapure water in the electronics industry.

Although ultrafiltration is an economical and efficient operation, its development is hindered by membrane fouling due to membrane blocking, cake formation or concentration polarization. Membrane fouling causes an increase in the membrane resistance a decrease in the permeate flux with time. Therefore, understanding how and when the membrane is fouled is worthy of further research. ${ }^{4}$ It must be also pointed out that membrane fouling increases the energy consumption and the operating costs. Moreover it requires frequent cleaning of the membranes. ${ }^{5}$ 
Several authors studied crossflow membrane ultrafiltration in terms of fouling resistances. Mondal and $\mathrm{De}^{6}$ studied two fouling mechanisms (complete pore blocking and cake layer) during crossflow membrane filtration and they obtained their resistance values. However, they comment that complete pore blocking followed by cake filtration was not enough to explain the flux decline data. Vladisavljevic et al. ${ }^{7}$ studied the variation of fouling resistance with filtration time and the effects of operating pressure and crossflow velocity in the ultrafiltration of depectinized apple juice.

In this work, the effect of operating conditions, transmembrane pressure (TMP) and crossflow velocity, on membrane resistance in the crossflow ultrafiltration of polyethylene glycol (PEG) were studied and compared to the predictions obtained with the complete blocking and intermediate blocking Hermia's models adapted to crossflow filtration. ${ }^{1}$ Moreover, the model parameters were theoretically estimated and their values were analysed and discussed.

\section{Theoretical estimation of the parameters of the complete and the intermediate blocking models for crossflow filtration}

The complete and the intermediate pore blocking models for crossflow filtration were described in detail in Vincent-Vela et al. ${ }^{8}$ According to the models equations, the theoretical estimation of the parameters of these models ${ }^{1}$ allows the prediction of permeate flux with time using only two experimental values: the initial and the steadystate permeate flux. 
The parameters of the models named $K_{c}$ and $K_{i}$ for the complete and intermediate blocking models, $K$, respectively; are equal and estimated by means of Eq. (1) ${ }^{9}$

$$
K=\frac{3}{4} \cdot \frac{\rho_{m} \cdot X_{m}}{\rho_{s} \cdot a_{p} \cdot \psi}
$$

In Eq (1), the form factor of the solute molecule, $\Psi$, is equal to the largest dimension of the molecule divided by the smallest dimension of the molecule. The parameters $\rho_{m}$ and $X_{m}$ can be estimated by means of Eqs. (2) and (3), respectively. For that purpose, the solute concentration over the membrane surface, $C_{m}$, must be estimated first.

$$
\begin{gathered}
\rho_{m}=C_{m}+\rho \cdot\left(1-\frac{C_{m}}{\rho_{s}}\right) \\
X_{m}=\frac{C_{m}}{\rho \cdot\left(1-\frac{C_{m}}{\rho_{s}}\right)+C_{m}}
\end{gathered}
$$

The variable $C_{m}$ is related to the steady-state permeate flux, $J_{P s s}$, according to Eq. (4) ${ }^{10}$

$$
J_{P S s}=k_{T M} \cdot \ln \left(\frac{C_{m}-C_{P}}{C_{0}-C_{P}}\right)
$$

The mass transfer coefficient, $k_{T M}$, for turbulent flow is estimated by means of Eq. $(5)^{10}$

$$
k_{T M}=0.023 \cdot R e^{0.8} \cdot S c^{0.33} \cdot \frac{D}{D_{\text {int }}}
$$


where $R e$ and $S c$ are the Reynolds and the Schmidt number, respectively. They are calculated according to Eqs. (6) and (7).

$R e=\frac{D_{\text {int }} \cdot v_{\text {tang }} \cdot \rho}{\mu}$

$S c=\frac{v}{D}$

\section{Fouling experiments}

PEG with a molecular weight of 35000 Da (Merck-Schuchardt (Germany)) was used in the UF experiments at a concentration of $5 \mathrm{~g} / \mathrm{L}$. Carbosep M2 monotubular ceramic membranes (Orelis, S.A. (France)) with a membrane area of $35.5 \mathrm{~cm}^{2}$ and a molecular weight cut off (MWCO) of $15 \mathrm{kDa}$ were tested. Crossflow ultrafiltration experiments were performed in the pilot plant described elsewhere. ${ }^{11,12}$ The procedure of fouling experiments can be found in Vincent-Vela et al. ${ }^{8}$

\section{Results and discussion}

The predictions for the complete blocking and the intermediate blocking models with theoretical estimation of the model parameters is illustrated in Fig. 1 and 2, respectively. The experimental data is represented by symbols and the fitted curves are represented by lines. Selection of the best model can only be performed when high flux decline is observed because a high precision in both models predictions is obtained in other cases 
(high crossflow velocities and low TMPs). For this reason, the analysis of the results is based on the data that correspond to the following experimental conditions: a TMP of $0.4 \mathrm{MPa}$ and a crossflow velocity of $1 \mathrm{~m} / \mathrm{s}$; a TMP of $0.3 \mathrm{MPa}$ and a crossflow velocity of $1 \mathrm{~m} / \mathrm{s}$ and a TMP of $0.4 \mathrm{MPa}$ and a crossflow velocity of $2 \mathrm{~m} / \mathrm{s}$.

In a previous work ${ }^{8}$, it was observed that the intermediate blocking model fitted best to the experimental data than the complete blocking model. When the parameters of these models are theoretically estimated (Fig. 1 and 2) these results are confirmed for the most severe fouling conditions tested $(1 \mathrm{~m} / \mathrm{s}$ and $0.4 \mathrm{MPa})$.

\section{Insert Figure 1 about here.}

In the intermediate blocking model, molecules are allowed to settle on previously deposited particles. It is assumed that each location has an equal probability of being occupied. This means that the chance that a particle settles on a free site is equal to the ratio of free and occupied sites. ${ }^{5}$ It must be also noted that the intermediate blocking model adapted to crossflow ultrafiltration considers that the size of the solute molecules is similar to the membrane pore size. Therefore, membrane pore blocking occurs in the entrance of the membrane pores, which can be partially blocked or sealed. Although there is a great difference between the molecular weight of PEG, $35000 \mathrm{~g} / \mathrm{mol}$, and the MWCO of the membrane, $15000 \mathrm{~g} / \mathrm{mol}$, measured membrane PEG retention was $86 \%$. It is believed that linear, water soluble polymer molecules, such as PEG molecules, are able to snake through the membrane pores. ${ }^{2}$ The intermediate blocking model adapted to crossflow filtration explains this situation better than complete blocking model adapted to crossflow filtration because it considers that partial pore blocking may occur. 
The PEG molecules that snake through the membrane pores can cause this type of fouling.

In the complete blocking model adapted to crossflow filtration the size of the solute molecules is greater than that of the membrane pores, thus this model assumes that solute molecules are completely retained by the membrane and the pores are sealed. No partial blocking of the membrane pores is considered. It is assumed that each filtrated particle participates in blocking the membrane without any superposition. ${ }^{13}$ Furthermore, it is assumed that the resistance is inversely proportional to the fraction of free pores. ${ }^{5}$ Moreover, the intermediate blocking model adapted to crossflow filtration describes more accurately a real ultrafiltration process than the complete blocking model adapted to crossflow filtration. In the first one, solute molecules can superimpose over others that have previously covered up the membrane surface.

\section{Insert Figure 2 about here.}

In previous work, ${ }^{8}$ the results showed that the models fitted with the same accuracy to experimental data for the following experimental conditions: a $v_{\text {tang }}$ of $1 \mathrm{~m} / \mathrm{s}$ and a TMP of $0.3 \mathrm{MPa}$ and in the case of a $v_{\text {tang }}$ of $2 \mathrm{~m} / \mathrm{s}$ and a TMP of $0.4 \mathrm{MPa}$. However, when the parameters of the models are theoretically estimated (Fig. 1a, 1b, 2a and 2b) the complete blocking model adapted to crossflow ultrafiltration fits slightly better to the experimental results than the intermediate blocking model adapted to crossflow filtration. For these experimental conditions the accumulation of solute molecules over the membrane surface is lower than in the case of a crossflow velocity of $1 \mathrm{~m} / \mathrm{s}$ and a TMP of 0.4 MPa, less solute molecules can superimpose over others and a lesser 
amount of molecules can snake through the membrane pores. Measured PEG retention was higher than in the case of a crossflow velocity of $1 \mathrm{~m} / \mathrm{s}$ and a TMP of $0.4 \mathrm{MPa}$.

Better predictions are obtained when the models are fitted to the experimental data ${ }^{8}$ than when their parameters are theoretically estimated. Nevertheless, in the last case the precision in the predictions is also very high.

In Fig. 1 and 2 it can be observed that the membrane fouling resistance, $R_{f}$, increases with TMP for a constant $v_{\text {tang. }}$. Similar results were reported by Kwon et al. ${ }^{14}$ In the case of $v_{\text {tang }}$, it seems to have a positive effect upon $R_{f}$. The increase in $v_{\text {tang }}$ produces a higher turbulence near the membrane surface. As a consequence, concentration polarization and the formation of a fouling layer is less favourable and an increase of $v_{\text {tang }}$ has a marked beneficial effect on reducing fouling. ${ }^{15}$

\section{Insert Table 1 about here.}

A better understanding of the phenomenological processes occurring during filtration can be obtained by examining the best fit for the single parameter models. ${ }^{5}$ Table 1 shows the theoretically estimated parameters for the complete blocking and the intermediate blocking Hermia's models. When the parameters of the model are estimated by means of fitting them to the experimental results, ${ }^{8}$ they decrease when the $v_{\text {tang }}$ increases, whereas they do not follow any pattern with TMP. On the other hand, when the parameters of the models are theoretically estimated (see Table1) their values increase with an increase in the TMP and with a decrease in the crossflow velocity. These results are consistent with the physical meaning and the definitions of the 
parameters of Hermia's models adapted to crossflow filtration (Eq. (1)), the values of these parameters should be higher when membrane fouling is more severe, i.e. high TMPs and low crossflow velocities. These operating conditions in membrane crossflow filtration favour the accumulation of molecules near the membrane surface, i.e. fouling.

According to table 1, when TMP increases, the theoretical values of the parameters of complete and intermediate blocking increase as well. This can be due to some molecules plugging the pores by bridging or transporting into pores, and thus the internal pore restrictions to fluid flow. ${ }^{16}$ Concerning to $v_{\text {tang }}$, it was observed that the theoretical values of the parameters of complete and intermediate blocking decreased when $v_{\text {tang }}$ increased. This can be explained by the thinner diffusion layer formed at high $v_{\text {tangs }}$. It is well known that the fouling layer will become thinner with increasing $v_{\text {tangs. }}$. On the other hand, an increase in $v_{\text {tang }}$ will cause the long chain macromolecules of the fouling layer formed to become finer due to the selective deposition caused by the crossflow effect. $^{16,17}$

An empirical correlation between the theoretical values of the parameters of complete and intermediate blocking, $\mathrm{K}$, and the operating conditions (TMP and $v_{\text {tang }}$ ) was determined by multiple linear regression analysis using statgraphics centurion XV. The equation of the fitted model for $\mathrm{K}$ was:

$K=5.19583-1.27125 \cdot v_{\text {tang }}+24.9533 \cdot T M P$

where $\mathrm{K}$ is given in $\mathrm{m}^{-1}$, $v_{\text {tang }}$ is given in $\mathrm{m} / \mathrm{s}$ and TMP is given in MPa. 
The measure of fit, as per the $\mathrm{R}^{2}$, was 98.27. The Durbin-Watson statistic was 2.21 (pValue $=0.54)$. As this value was close to 2 , this confirms that the residuals vary ramdomly and there is no indication of serial autocorrelation in the residuals at the $95.0 \%$ confidence level. Moreover, the p-Value is greater than 0.05; therefore it confirms that there is not a significant correlation at the 5\% significance level. The Lag 1 residual autocorrelation was -0.12 . Since this value is near to cero there is not significant structure unaccounted for by the model.

Tables 2 and 3 show the ANOVA table obtained for K. In Table 2, the ANOVA analysis showed a p-value of 0.0000 for the model. Since this value is lower than 0.05 there is a significant relationship of the form specified by the model between $R_{f}$ and the 4 parameters considered at the $95.0 \%$ confidence level.

In table 3, the p-values that correspond to the different parameters studied (TMP and $v_{\text {tang }}$ ) are lower to 0.05 . Therefore, there is a statistically significant relationship between the variables considered at the $95 \%$ confidence level.

A statistical multifactorial analysis (Table 4) of $\mathrm{K}, v_{\text {tang }}$ and TMP was also performed using statgraphics centurion $\mathrm{XV}$. This analysis is able to quantify all the possible complex conjugated effects of the parameters considered. ${ }^{18}$ It shows what operating conditions, squared effects and interactions among factors are more significant in the response variable, $\mathrm{K}$. The lower the $\mathrm{p}$-value is, the more significant the influence of a factor on the response variable is. According to the p-values shown in Table 4, it can be observed that both TMP and $v_{\text {tang }}$ have a remarkable influence on $\mathrm{K}$, since they have a $\mathrm{p}$-value practically equal to zero. Moreover, $v_{\text {tang }}$ has more influence in $\mathrm{K}$ than TMP, according to the p-values. However, the squared effects are not significant enough (pvalues higher than 0.05). This confirms that the proposed model for K (Eq. 8) as a function of $v_{\text {tang }}$ and TMP is correct and it should not include the squared effects.

\section{Conclusions}


Modelling membrane processes is interesting since it helps to choose an adequate TMP and a $v_{\text {tang }}$. This is positive from an operational point of view because by manipulating the operating conditions, it is possible to obtain a better control on membrane fouling processes.

For the two models considered in this work, the precision in the model predictions is very high for low fouling conditions.

For the experimental conditions that correspond to the highest fouling of the membrane, the intermediate blocking model fits best to the experimental data than the complete blocking model. For the rest of the experimental conditions evaluated, the complete blocking model fits slightly better to the experimental data than the intermediate blocking model.

In general, the values of the theoretically estimated parameters of Hermia's models adapted to crossflow filtration are higher when membrane fouling is more severe.

A model for the parameters of blocking models as a function of operating membrane conditions ( $\mathrm{v}_{\text {tang }}$ and TMP) was proposed in the case of membrane ultrafiltration of PEG.

\section{List of symbols}

$a_{p} \quad$ - radius of the solute molecule (m) 


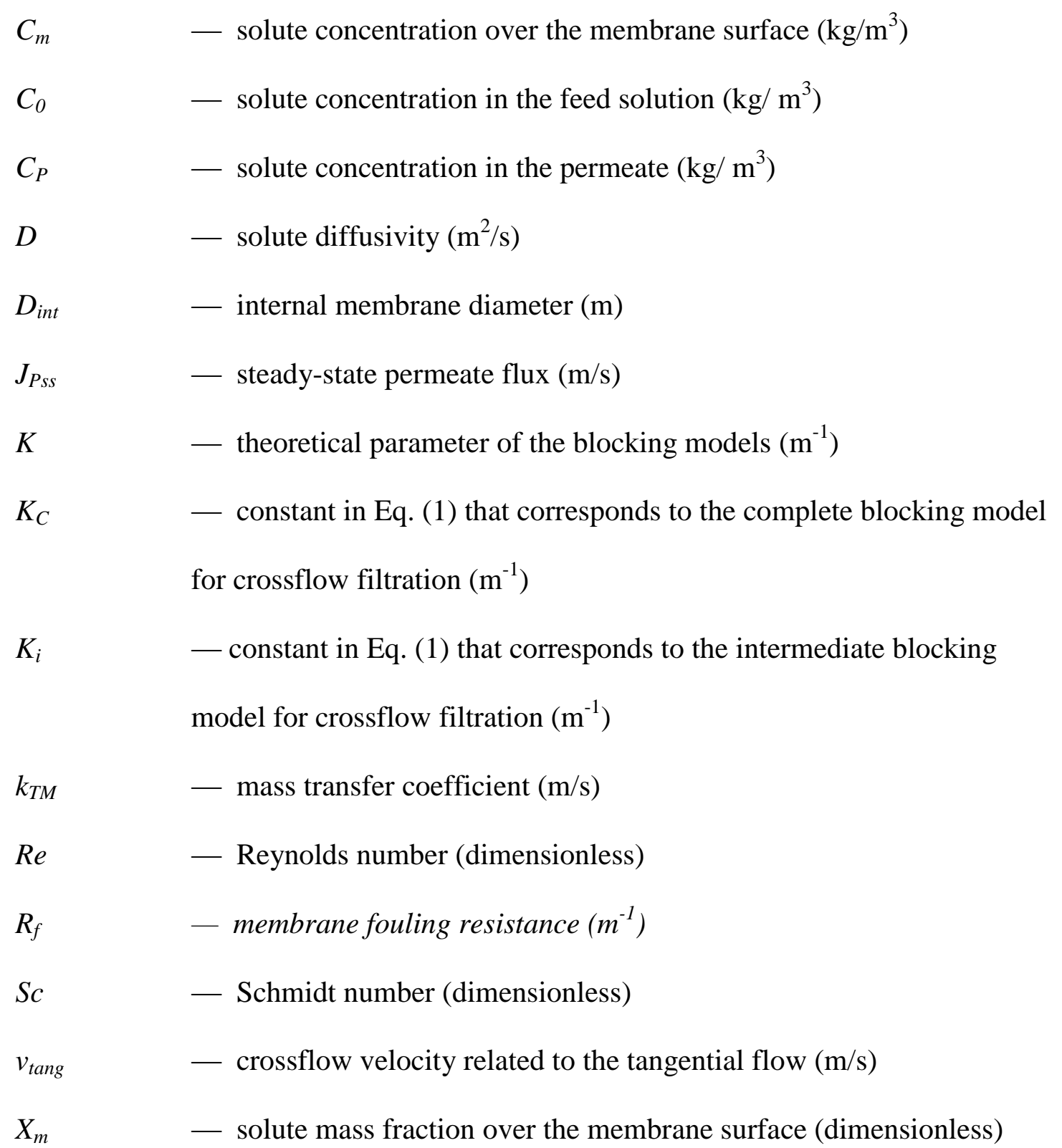

\section{Greek letters}

$$
\begin{array}{ll}
\mu & - \text { dynamic viscosity }(\mathrm{kg} / \mathrm{m} \mathrm{s}) \\
v & - \text { kinematic viscosity }\left(\mathrm{m}^{2} / \mathrm{s}\right) \\
\rho & - \text { solvent density }\left(\mathrm{kg} / \mathrm{m}^{3}\right) \\
\rho_{m} & - \text { density of the feed solution over the membrane surface }\left(\mathrm{kg} / \mathrm{m}^{3}\right) \\
\rho_{s} & - \text { solute density }\left(\mathrm{kg} / \mathrm{m}^{3}\right)
\end{array}
$$




\section{Acknowledgements}

The authors of this work wish to gratefully acknowledge the financial support of the Spanish Ministry of Science and Technology (MCYT) through its project no. CTQ2005-03398.

\section{References}

(1) Field, R. W.; Wu, D.; Howell, J. A.; Gupta, B. B. Critical flux concept for microfiltration fouling. J. Memb. Sci. 1995, 100, 259.

(2) Baker, R. W. Membrane technology and applications; Wiley: Chichester, 2004.

(3) Cheryan, M.; Alvarez, J.R. Membrane Separation Technology: Principles and Applications. Food and beverage industry applications; Stern-Elsevier: Amsterdam, 1995.

(4) Hwang, K.J.; Liao, C.Y.; Tung, K.L. Analysis of particle fouling during microfiltration by use of blocking models. J. Memb. Sci. 2007, 287, 287.

(5) Blankert, B.; Betlem, B. H.L; Roffel B. Dynamic optimization of a dead-end filtration trajectory: Blocking filtration laws. J. Membr. Sci. 2006, 285, 90.

(6) Mondal, S.; De, S. Generalized criteria for identification of fouling mechanism under steady state membrane filtration. J. Membr Sci. 2009, 344, 6.

(7) Vladisavljevi, G. T.; Vukosavljevi, P.; Bukvi, B. Permeate flux and fouling resistance in ultrafiltration of depectinized apple juice using ceramic membranes. $J$. Food Eng. 2003, 60, 241. 
(8) Vincent-Vela, M.C.; Álvarez-Blanco, S.; Lora-García, J.; Bergantiños-Rodríguez, E. Analysis of membrane pore blocking models adapted to crossflow ultrafiltration in the ultrafiltration of PEG. Chem. Eng. J. 2009, 149, 232.

(9) Zeng, J.; Ye, H.; Hu, Z. Application of the hybrid complexation-ultrafiltration process for metal ion removal from aqueous solutions. J. Hazard. Mater. 2009, 161, 1491.

(10) Cheryan, M. Ultrafiltration and microfiltration handbook; CRC Press: New York, 1998.

(11) Vincent-Vela, M.C.; Álvarez-Blanco, S.; Lora-García, J.; Gozálvez-Zafrilla, J.M.; Bergantiños-Rodríguez, E. Utilization of a shear induced diffusion model to predict permeate flux in the crossflow ultrafiltration of macromolecules. Desalination 2007, 206, 61 .

(12) Vincent-Vela, M.C.; Álvarez-Blanco, S.; Lora-García, J.; Gozálvez-Zafrilla, J.M.;

Bergantiños-Rodríguez, E. Modelling of flux decline in crossflow ultrafiltration of macromolecules: comparison between predicted and experimental results. Desalination 2007, 204, 328.

(13) Purkait, M.K.; Bhattacharya, P.K.; De, S. Membrane filtration of leather plant effluent: Flux decline mechanism. J. Membr. Sci. 2005, 258, 85.

(14) Kwon, B.; Molek, J.; Zydney, A.L.Ultrafiltration of PEGylated proteins: Fouling and concentration polarization effects. J. Membr. Sci. 2008, 319, 206.

(15) Llanos, J.; Pérez, A.; Cañizares, P. Water-soluble polymer ultrafiltration process at pilot scale: Study of hydrodynamics and factors limiting flux. J. Membr. Sci. 2009, 341, 37.

(16) Li, M.; Zhao, Y.; Zhou, S.; Xing, W.; Wong, F.S. Resistance analysis for ceramic membrane microfiltration of raw soy sauce. J. Membr. Sci. 2007, 299, 122. 
(17) Zhao, Y.; Xing, W.; Xu, N.; Shi, J. Hydraulic resistance in microfiltration of titanium white waste acid through ceramic membranes. Sep. Purif. Tech. 2003, 32, 99. (18) Martí-Calatayud, M.C.; Vincent-Vela, M.C.; Álvarez-Blanco, S.; Lora-García, J.; Bergantiños-Rodríguez, E. Analysis and optimization of the influence of operating conditions in the ultrafiltration of macromolecules using a response surface methodological approach. Chem. Eng. J. 2010, 156, 337. 


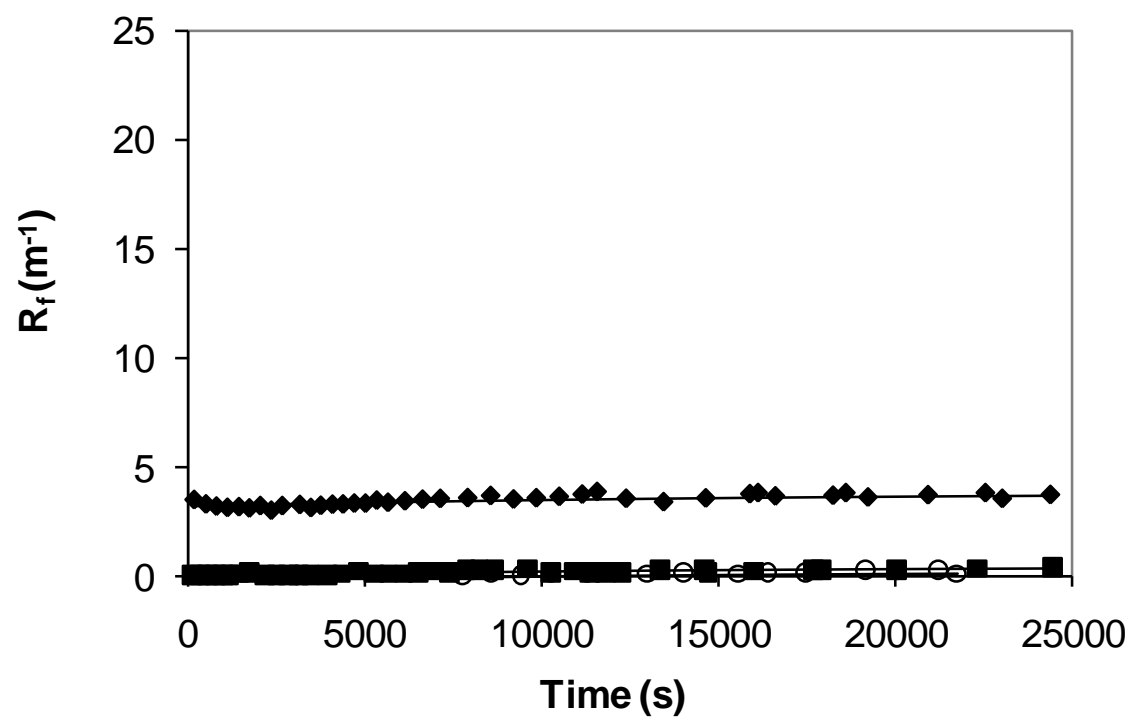

Fig. 1a.

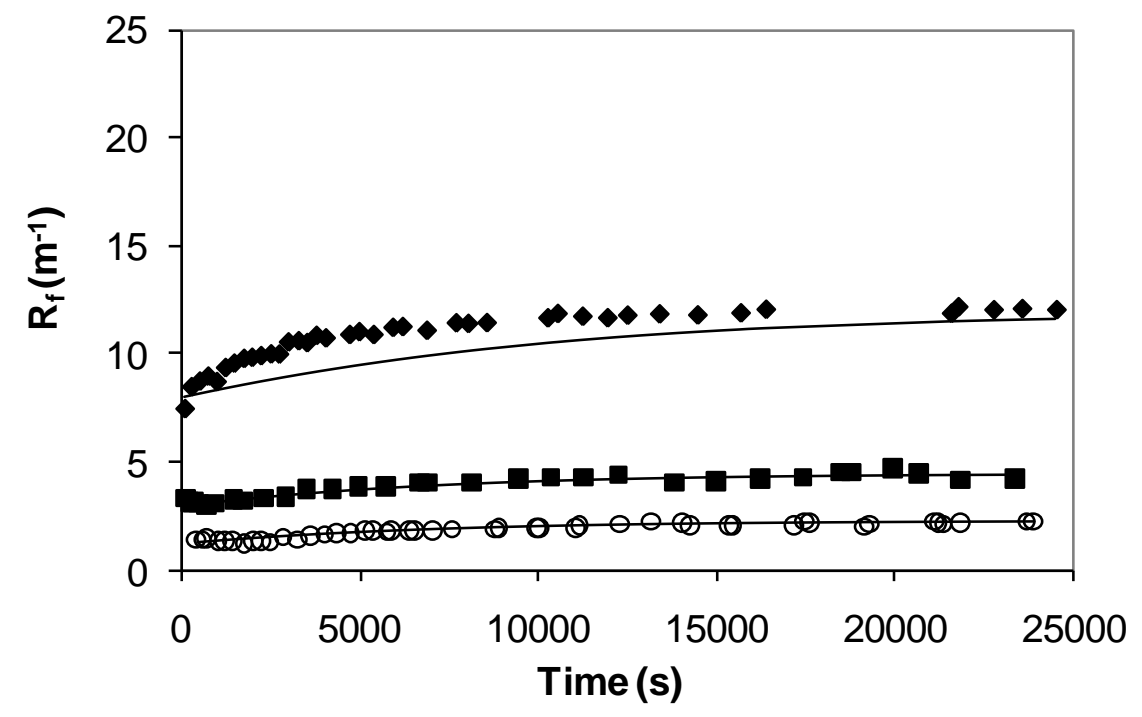

Fig. 1b 


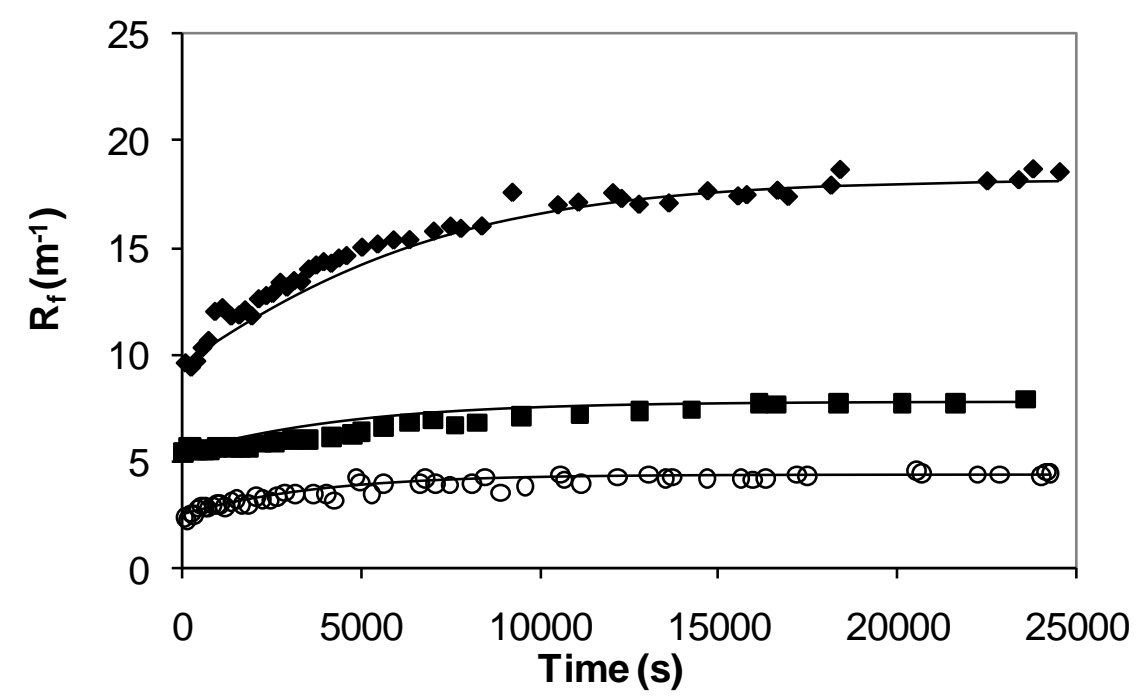

Fig. 1c

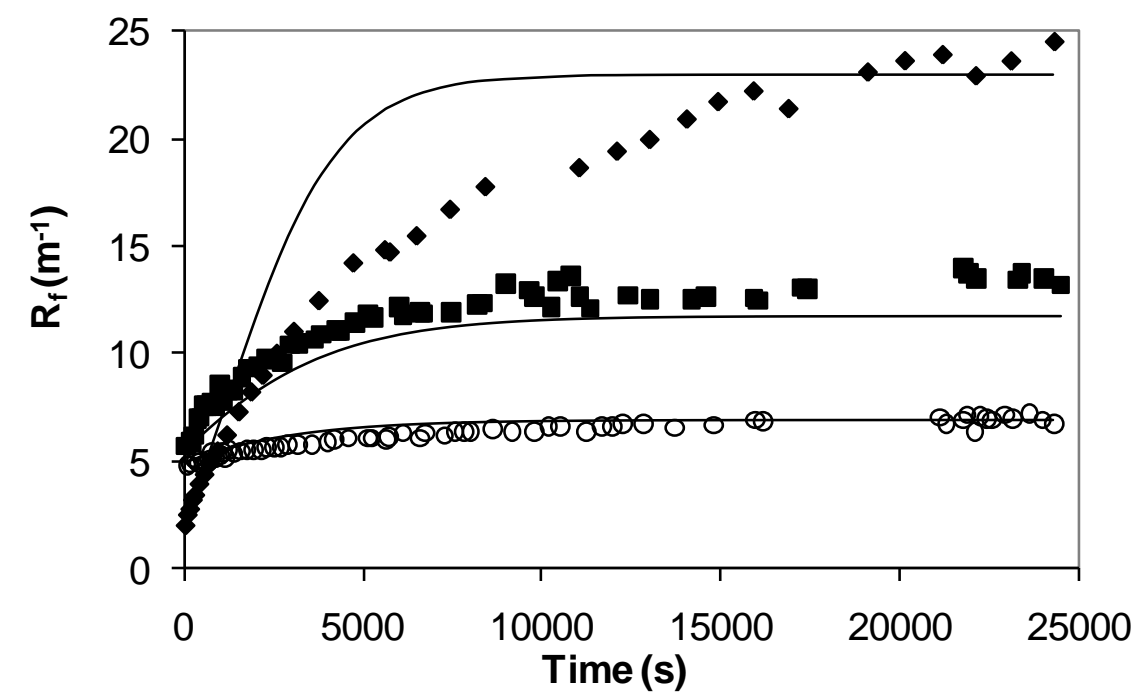

Fig. 1d

Fig. 1. Fouling resistance experimental and fitted values using complete blocking model as a function of $v_{\text {tang }}$ for a solute concentration of $5 \mathrm{~g} / \mathrm{L}$. (a) $0.1 \mathrm{MPa}$. (b) $0.2 \mathrm{MPa}$. (c) $0.3 \mathrm{MPa}$. (d) $0.4 \mathrm{MPa} .1 \mathrm{~m} / \mathrm{s} ; \mathbf{m} 2 \mathrm{~m} / \mathrm{s} ; \circ 3 \mathrm{~m} / \mathrm{s}$. 


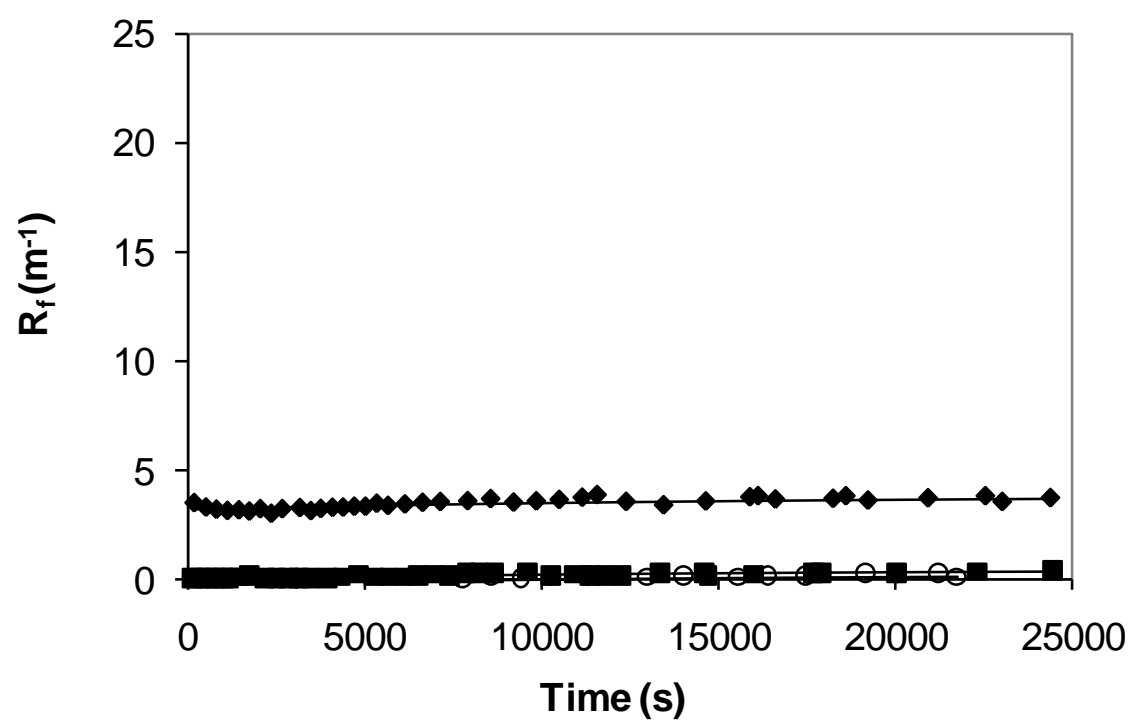

Fig. 2a

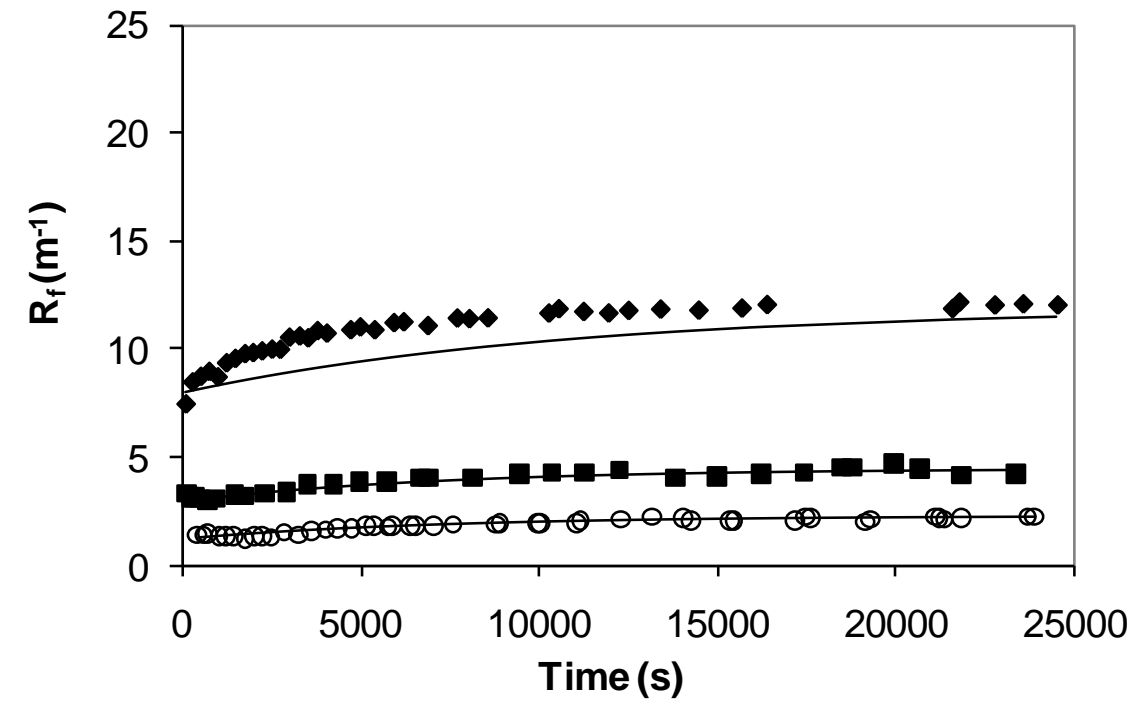

Fig. $2 b$ 


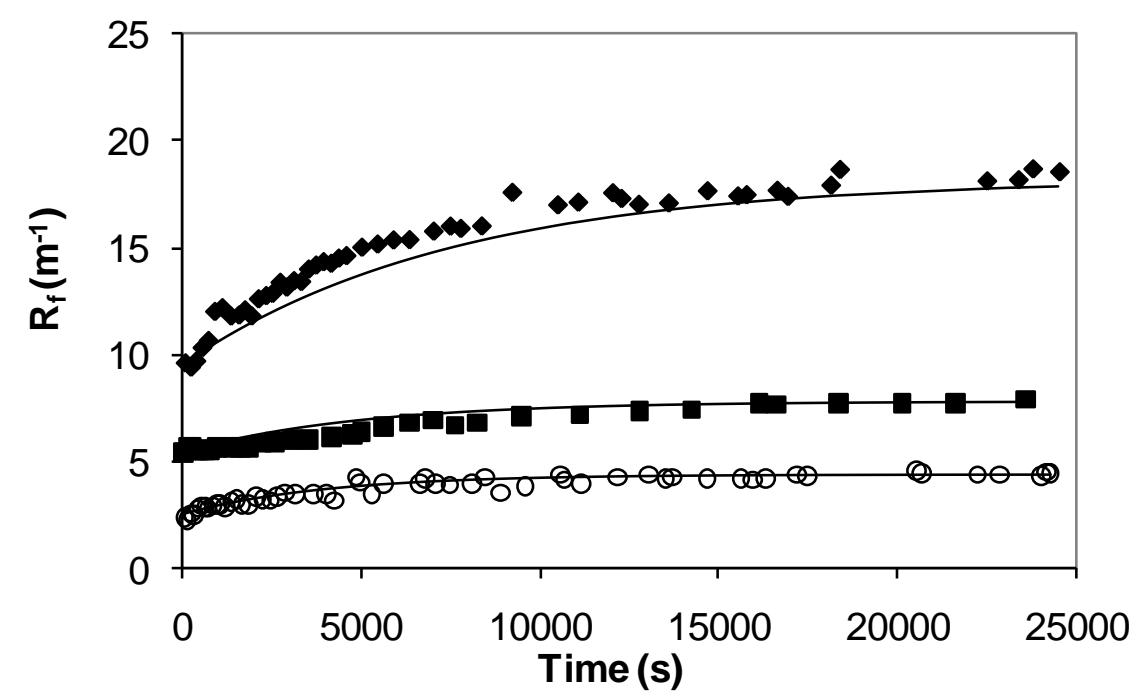

Fig. 2c

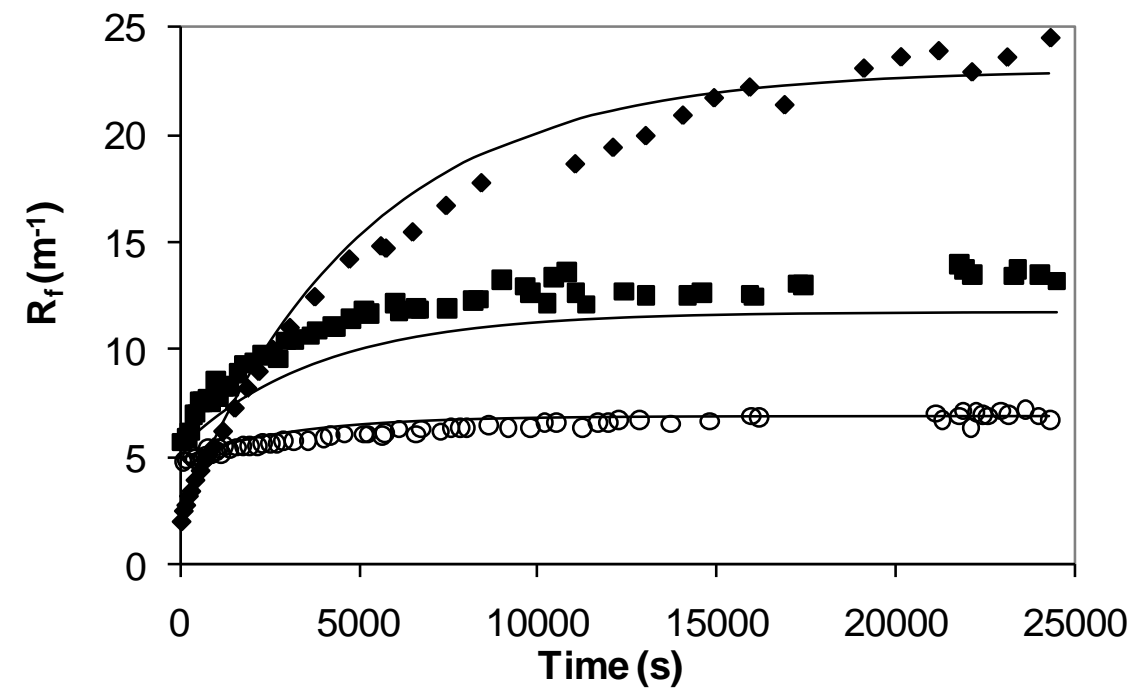

Fig. $2 d$

Fig. 2. Fouling resistance experimental and fitted values using intermediate blocking model as a function of $v_{\text {tang }}$ for a solute concentration of $5 \mathrm{~g} / \mathrm{L}$. (a) $0.1 \mathrm{MPa}$. (b) 0.2 MPa. (c) $0.3 \mathrm{MPa}$. (d) $0.4 \mathrm{MPa}$ - $1 \mathrm{~m} / \mathrm{s}$; $2 \mathrm{~m} / \mathrm{s}$; $\circ 3 \mathrm{~m} / \mathrm{s}$. 
Table 1. Theoretically and empirically estimated parameters of complete blocking and intermediate blocking Hermia's models adapted to crossflow ultrafiltration.

\begin{tabular}{ccc}
\hline TMP (MPa) & Crossflow velocity $(\mathrm{m} / \mathrm{s})$ & $K_{c t}$ and $K_{i t}\left(\mathrm{~m}^{-1}\right)$ \\
\hline \multirow{3}{*}{0.1} & 1 & 6.61 \\
& 2 & 4.97 \\
& 3 & 4.06 \\
\hline \multirow{2}{*}{0.2} & 1 & 8.60 \\
& 2 & 7.79 \\
& 3 & 6.30 \\
\hline \multirow{3}{*}{0.3} & 1 & 11.15 \\
& 2 & 9.77 \\
& 3 & 9.40 \\
\hline \multirow{2}{*}{0.4} & 1 & 14.79 \\
& 2 & 12.04 \\
\hline
\end{tabular}

Table 2. ANOVA table for $\mathrm{k}$ : Analysis of variance.

\begin{tabular}{cccccc}
\hline Source & $\begin{array}{c}\text { Sum of } \\
\text { Squares }\end{array}$ & $\begin{array}{c}\text { Degrees of } \\
\text { freedom }\end{array}$ & Mean Square & F-Ratio & P-Value \\
\hline Model & 106.329 & 2 & 53.1645 & 255.81 & 0.0000 \\
Residual & 1.87043 & 9 & 0.207825 & & \\
Total (Corr.) & 108.199 & 11 & & & \\
\hline
\end{tabular}

Table 3. ANOVA table for K: Coefficient analysis.

\begin{tabular}{ccccc}
\hline Parameter & Estimate & Standard Error & T-Statistic & P-Value \\
\hline Constant & 5.19583 & 0.455879 & 11.3974 & 0.0000 \\
$v_{\text {tang }}$ & -1.27125 & 0.161177 & -7.88727 & 0.0000 \\
TMP & 24.9533 & 1.17707 & 21.1995 & 0.0000
\end{tabular}


Table 4. ANOVA table for k: Analysis of simple and coupled effects of TMP and $v_{\text {tang. }}$.

\begin{tabular}{cccccc}
\hline Source & $\begin{array}{c}\text { Sum of } \\
\text { Squares }\end{array}$ & $\begin{array}{c}\text { Degrees of } \\
\text { freedom }\end{array}$ & Mean Square & F-Ratio & P-Value \\
\hline A:TMP & 9.70282 & 1 & 9.70282 & 37.37 & 0.0017 \\
B: $v_{\text {tang }}$ & 12.9286 & 1 & 12.9286 & 49.80 & 0.0009 \\
AA & 0.0186889 & 1 & 0.0186889 & 0.07 & 0.7992 \\
AB & 0.157502 & 1 & 0.157502 & 0.61 & 0.4713 \\
BB & 0.372504 & 1 & 0.372504 & 1.43 & 0.2847 \\
Total error & 1.29805 & 5 & 0.25961 & & \\
Total (corr.) & 108.199 & 11 & & & \\
\hline
\end{tabular}

